\title{
Record of the Genus Litus Haliday (Hymenoptera: Chalcidoidea: Mymaridae) from India, with description of two species
}

\author{
Tabassum Rehmat ${ }^{1}$, Shoeba Binte Anis ${ }^{1} \&$ Mohammad Hayat ${ }^{2}$ \\ 1,2 Department of Zoology, Aligarh Muslim University, Aligarh, Uttar Pradesh 202002, India \\ Email: ${ }^{2}$ mohd_hayat@ rediffmail.com (Corresponding author)
}

Date of online publication 26 July 2009 ISSN 0974-7907 (online) | 0974-7893 (print)

Editor: T.C. Narendran

\section{Manuscript details:}

Ms \# 02199

Received 06 May 2009

Finally accepted 17 July 2009

Citation: Rehmat, T., S.B. Anis \& M. Hayat (2009). Record of the Genus Litus Haliday (Hymenoptera: Chalcidoidea: Mymaridae) from India, with description of two species. Journal of Threatened Taxa 1(7): 370-374.

Copyright: (c) Tabassum Rehmat, Shoeba Binte Anis \& Mohammad Hayat 2009. Creative Commons Attribution 3.0 Unported License. JoTT allows unrestricted use of this article in any medium for non-profit purposes, reproduction and distribution by providing adequate credit to the authors and the source of publication.

Author Details: Ms T. REHMAT is a research student working on the Indian Mymaridae under the guidance of Dr (MRS) S.B. ANIS, PhD. is a Lecturer in Zoology, and Co-Principal Investigator in the ICAR Network Project on Insect Biosystematics. Dr. M. HaYat, PhD., D.Sc., is the Principal Investigator in the ICAR Project.

Author Contribution: The main work of preparation of the paper, writing and description was done by the first author, with considerable inputs, including checking of the final draft of the manuscript done by the other two authors.

Acknowledgement: We are thankful to the Indian Council of Agricultural Research, New Delhi, and Dr. V.V. Ramamurthy, Division of Entomology, Indian Agricultural Research Institute, New Delhi, the National Coordinato of the "Network Project on Insect Biosystematics" for financial assistance. We are also grateful to the Aligarh Muslim University and to the Chairman, Department of Zoology, for providing working facilities.

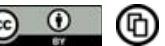

OPEN ACCESS | FREE DOWNLOAD
Abstract: The mymarid genus Litus Haliday is recorded from India for the first time, and two new species, L. huberi Rehmat \& Anis, sp. nov., and L. triapitsyni Rehmat \& Hayat, sp. nov. are described from material collected from the state of Assam.

Keywords: Genus Litus, Hymenoptera, India, Mymaridae, new species.

Recently, three specimens of the mymarid genus Litus Haliday were collected from Guwahati (Assam, India). With the help of Dr. J. Huber (Ottawa, Canada) and Dr. S.V. Triapitsyn (Riverside, U.S.A.) we studied the samples.

The genus Litus is a new record from India. And this paper deals with the descriptions of two new species.

\section{Genus Litus Haliday}

Litus Haliday, 1833: 269, 345. Type species Litus cynipseus Haliday 1833, by designation of Gahan \& Fagan, 1923: 81.

Neolitus Ogloblin, 1935: 60. Type species Neolitus argentinus Ogloblin, 1935, by original designation. Synonymy by Triapitsyn \& Berezovskiy, 2004: 3.

\section{Diagnosis}

Female. Body robust, highly sclerotized; head and thorax strongly sculptured. Mandible unidentate or bidentate, sometimes longer than malar space. Antennal formula, 1161; funicle segments without longitudinal sensilla; clava unsegmented, usually with 4 longitudinal sensilla. Mesoscutum usually with distinct notauli; scutellum with distinct anterior and posterior parts, the latter longer than the former; mesopostphragma projecting into gaster and usually with apex rounded. Fore and hind wings long and narrow, with very long marginal fringe; marginal vein of fore wing long. Legs with coxae usually strongly reticulate; tarsi 5-segmented. Petiole broader than long. Gaster with first tergite long; ovipositor length variable, either short or long, and hidden or slightly to strongly exserted at apex.

Hosts

Gregarious egg parasitoids of large Staphylinidae (Coleoptera) (Triapitsyn \& Berezovskiy 2004)

\section{Species and distribution}

The genus Litus contains 12 extant species including the two described here. It is nearly cosmopolitan, known from all the zoogeographical regions, except Australia and New Zealand. The Oriental Region species we know till now are from Thailand (L. sutil Triapitsyn \& Berezovskiy), Taiwan (China) (L. camptopterus Novicky), and Nepal (L. usach Triapitsyn \& Berezovskiy).

The species L. enocki Howard (1896) from Sri Lanka has been transferred to Camptoptera by Triapitsyn \& Berezovskiy (2004).

\section{Litus huberi Rehmat \& Anis sp.nov. \\ (Images 1-6, Fig. 1)}

Material examined

Holotype: Female, 28.x.2008, on slide under 3 coverslips, Kontola, Guwahati, Assam, India, coll. F.R. Khan. Deposited in The National Pusa Collection, Division of 


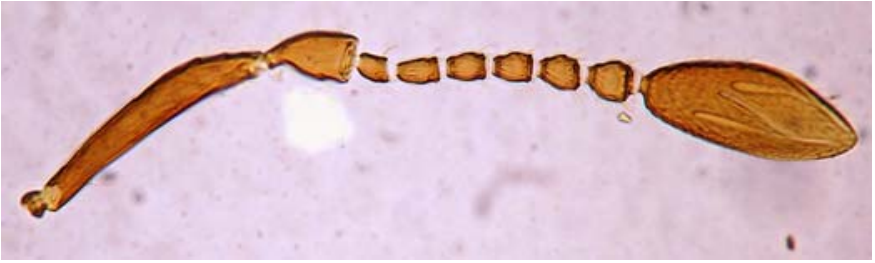

Image 1. Litus huberi Rehmat \& Anis, sp. nov., female: Antenna.

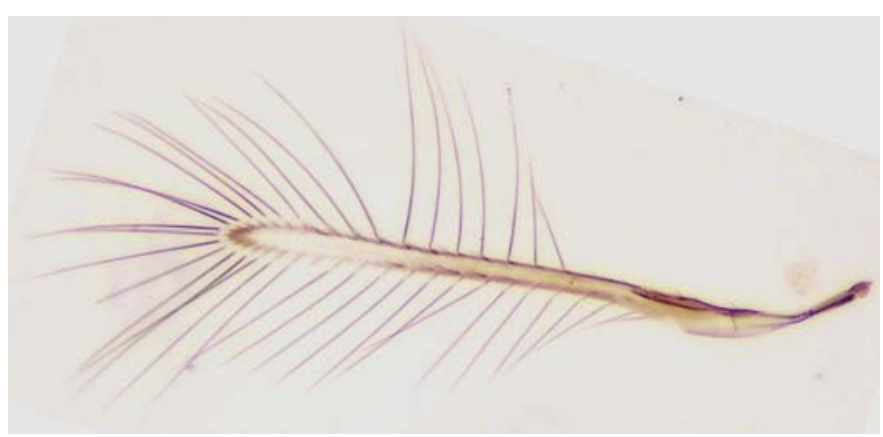

Image 2. Litus huberi Rehmat \& Anis, sp. nov., female: Fore wing.

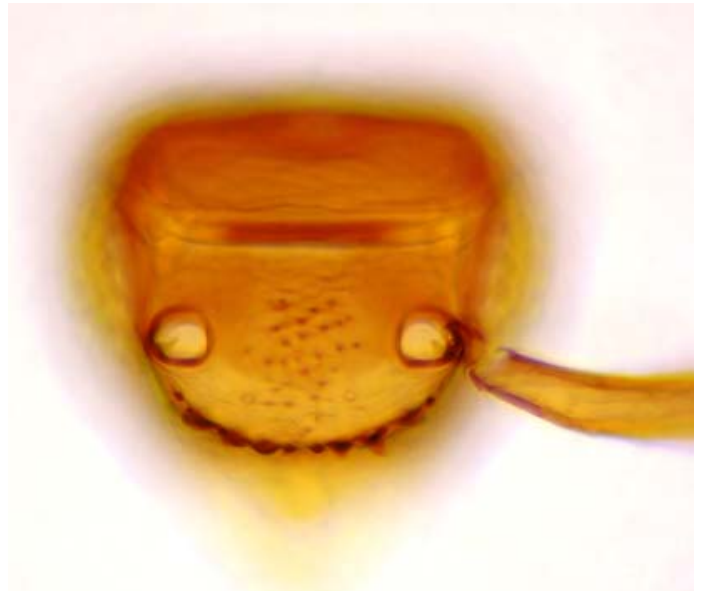

Image 3. Litus huberi Rehmat \& Anis, sp. nov., female: Head showing tubercles on frons and the line of denticles.

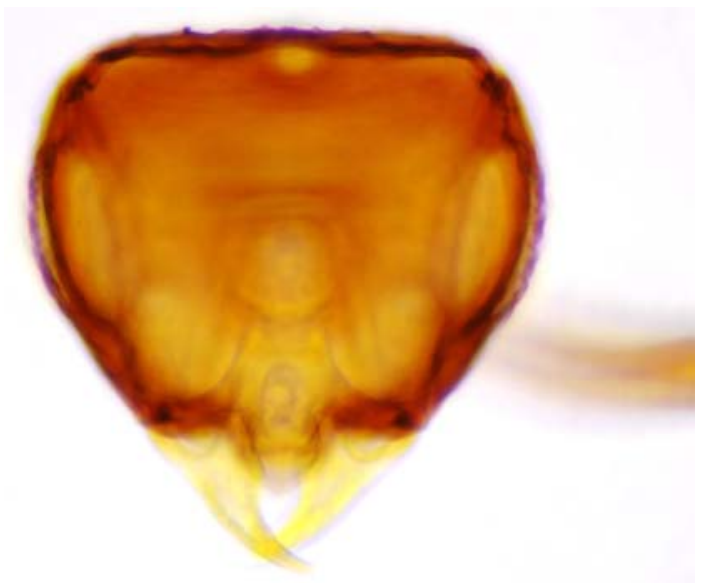

Image 4. Litus huberi Rehmat \& Anis, sp. nov., female: Head frontal view, showing mandibles.

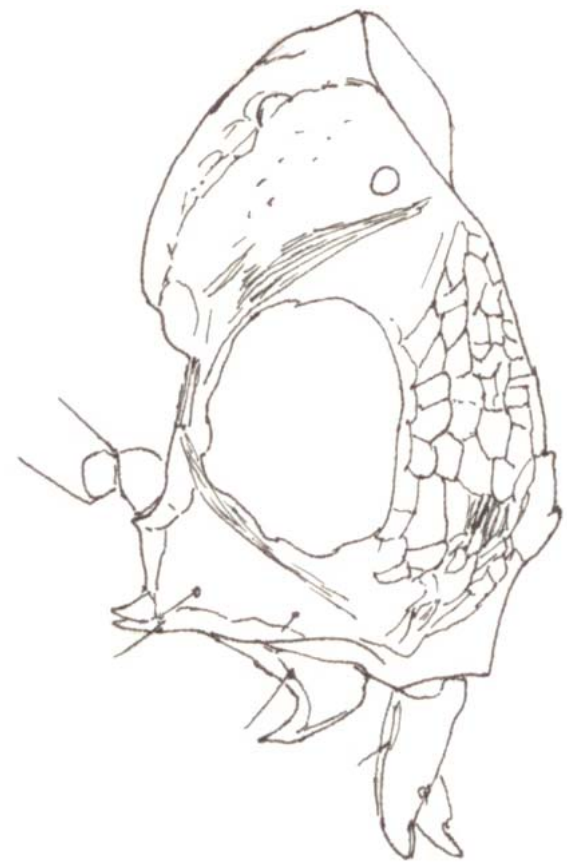

Figure 1. Litus huberi Rehmat \& Anis, sp. nov., female: Head, dorso-lateral view.

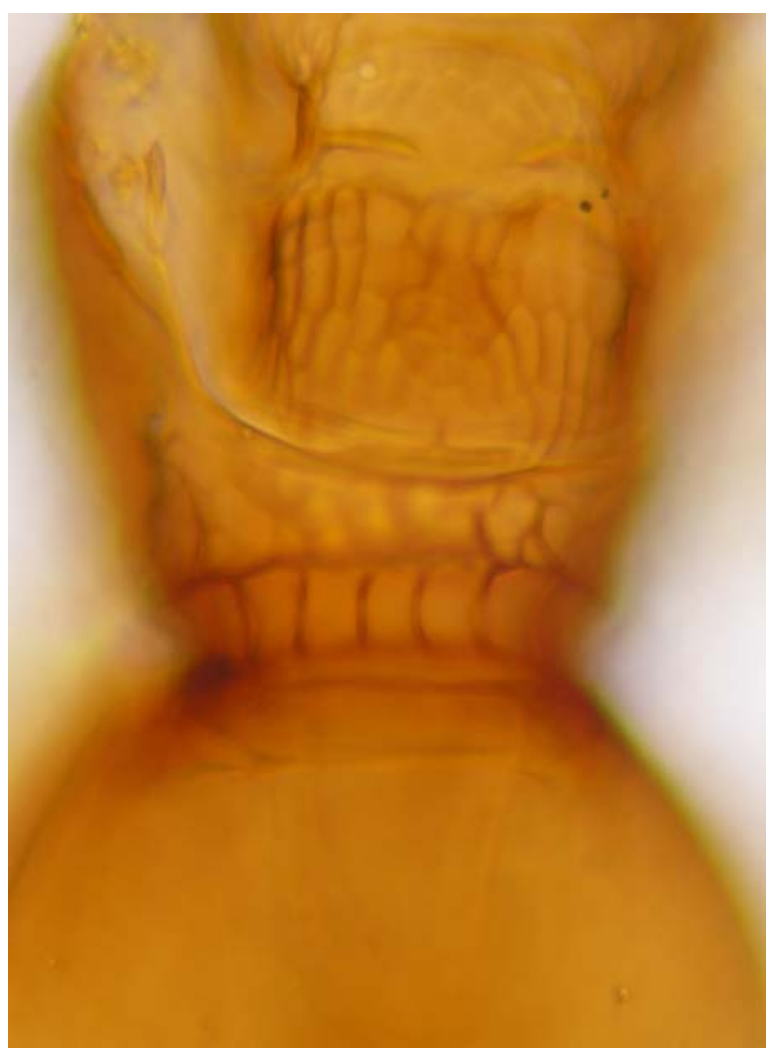

Image 5. Litus huberi Rehmat \& Anis, sp. nov., female: Scutellum and propodeum showing sculpture, dorsal view. 


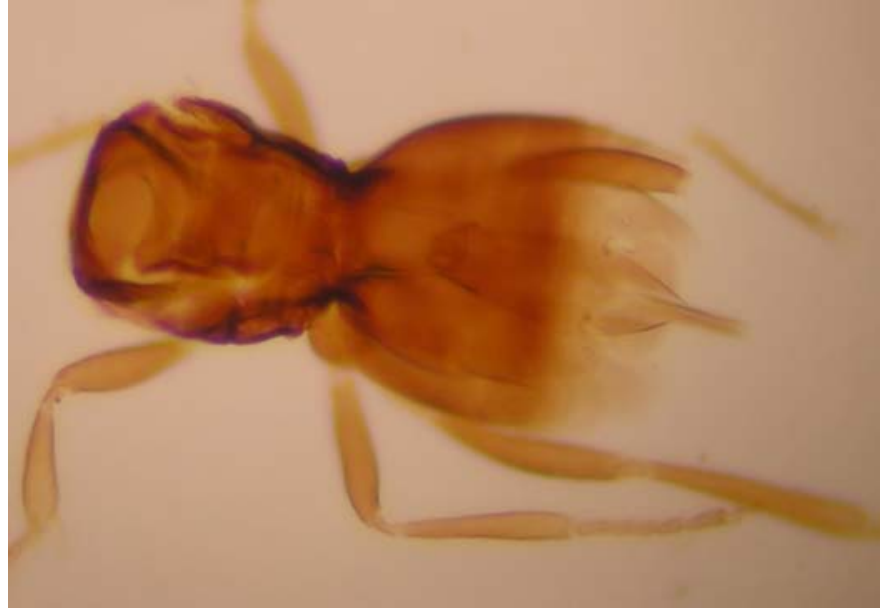

Image 6. Litus huberi Rehmat \& Anis, sp. nov., female: Thorax and gaster, dorsal view.

Entomology, Indian Agricultural Research Institute (NPCI), Reg.No. 13/6/70/3.

Paratype: 1 Female, 28.x.2008, on slide under 3 coverslips, Borkusi, Guwahati, Assam, India, coll. F.R. Khan. Deposited in Insect Collections, Department of Zoology, Aligarh Muslim University (ZDAMU), Reg.No. HYM/CH. 577.

\section{Etymology}

The species is named after Dr. J. Huber, Canadian Forest Service, Ottawa, Canada.

\section{Description}

Female: Length, $0.41 \mathrm{~mm}$ (Measured from card-mounted holotype before mounting it on slide). Body except distal three tergites of gaster which are brownish-yellow, dark brown to black, shiny; ovipositor sheaths dark brown. Mandibles pale yellow. Antennae dark brown. Fore wing lightly infuscate, hyaline in apical third; hind wing sub-hyaline. Legs with coxae black; femora and tibiae brown to dark brown; tarsi brownish.

Head: Frontovertex broad, about two-thirds of head width (34:53.5); frons with a slightly curved line of prominent denticles (Image 3); clypeus with a median apically pointed lobe (Fig. 1); antennal toruli removed from transverse trabecula by a distance slightly greater than diameter of a torulus; ocellar triangle with apical angle strongly obtuse; posterior ocelli nearly touching supraorbital trabecula; frons with several minute tubercles. Vertex with wide-meshed reticulations; temples strongly reticulate. Mandible unidentate, long, longer than malar space (Image 4; in Figure 1 mandibles appear shorter as the figure was drawn in dorso-lateral view). Antenna as in Image 1; scape, in lateral view as in triapitsyni, Rehmat \& Hayat sp.nov., but appears basally straight as it is oriented ventrally; first, fifth and sixth funicle segments (F1, F5, F6) quadratic, F2-4 slightly longer than broad, F2 longest; clava un-segmented, about $2.3 \mathrm{x}$ as long as broad, slightly shorter than preceding 5 funicle segments combined, and with 4 longitudinal sensilla.

Thorax: Compact, strongly sclerotized (characteristic of the genus); pronotum not visible in dorsal view of thorax, strongly reticulate, the cells laterally elongate and medially convergent; mesoscutum short, not more than half the length of scutellum, with raised reticulate sculpture, and with $2+2$ setae, mesoscutum without notaular lines; posterior scutellum with prominent raised reticulate sculpture (Image 5) compared to sculpture on anterior scutellum; propodeum posterior half behind transverse ridge narrowed and with prominent longitudinal ridges (Image $5)$. Fore wing disc (=blade) narrow, apically pointed (Image 2); and about $17.5 \mathrm{x}$ as long as broad (width measured at broadest point), if width of the blade is measured, the fore wing nearly $22 \mathrm{x}$ as long as broad; disc almost bare, except for 2-3 setae just distal of venation, and a row of 5 setae along posterior margin in middle of disc; venation characteristic of Litus species. Hind wing $24.5 \mathrm{x}$ as long as broad, similar to that in triapitsyni Rehmat \& Hayat, sp.nov. (as in Image 9), disc with a line of setae. Legs with coxae strongly sclerotized.

Gaster: Gaster longer than thorax (79:63); first tergite (TI) long, occupying nearly three-fourths of gaster length; other tergites appear strongly transverse (retracted within gaster); last tergite (TVII) apically conical; ovipositor short, and in slide mounted holotype, exserted to $0.17 \mathrm{x}$ of gaster length (Image 6). Relative measurements (holotype): ovipositor length, 73 [Lengths: mid tibia, 45; mid tarsus, 35; hind tibia, 56; hind tarsus, 55].

Male: Unknown.

Host: Unknown.

Comments: Litus huberi sp. nov. appears to be very close to L. sutil Triapitsyn \& Berezovskiy (2004) in having narrow fore wing blade, but differs from sutil in having funicle segments shorter, quadrate $(F 1,5,6)$ to only slightly longer than broad $(\mathrm{F} 2,3,4)$, clava about $2.3 \mathrm{x}$ as long as broad; fore wing disc straight; gaster $1.25 \mathrm{x}$ as long as thorax; and ovipositor occupying about three-fourths length of gaster, and clearly longer than both mid and hind tibiae, 1.62x as long as mid

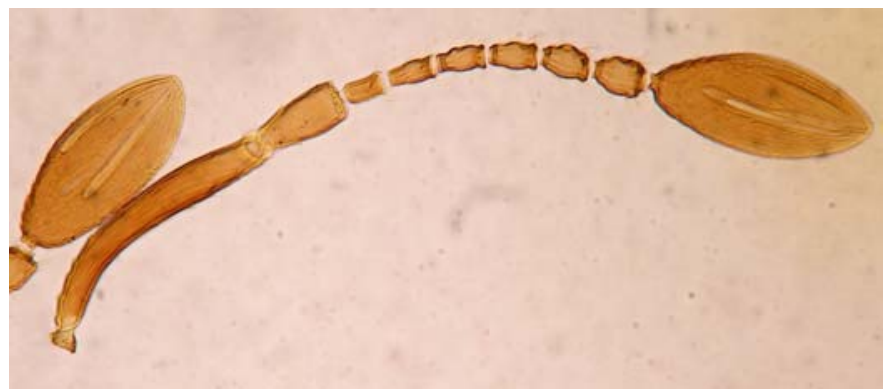

Image 7. Litus triapitsyni Rehmat \& Hayat, sp. nov., female: Antenna.

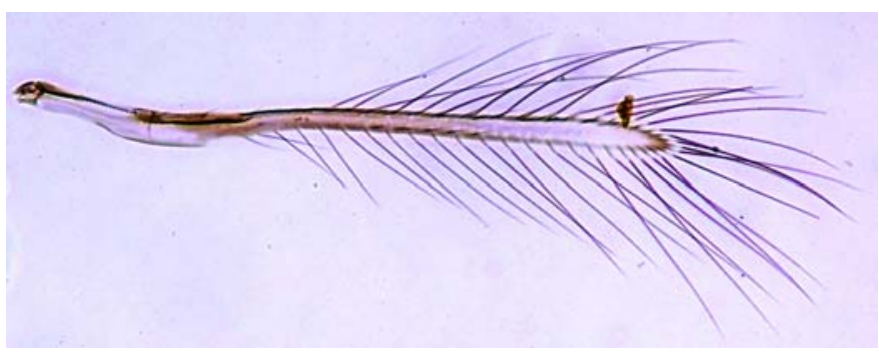

Image 8. Litus triapitsyni Rehmat \& Hayat, sp. nov., female: Fore wing. 


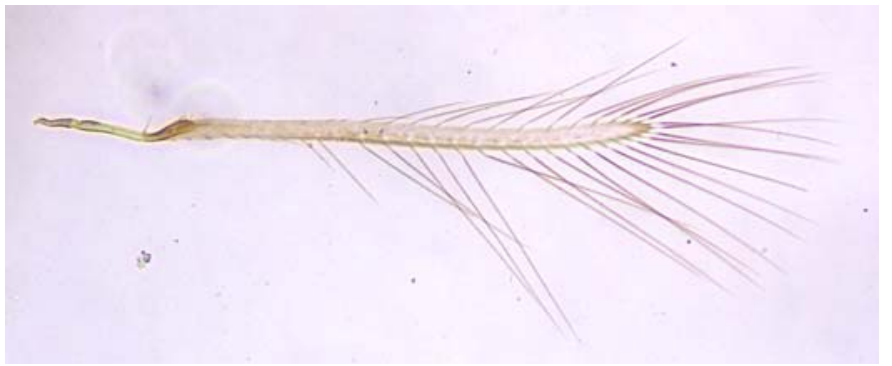

Image 9. Litus triapitsyni Rehmat \& Hayat, sp. nov., female: Hind wing.

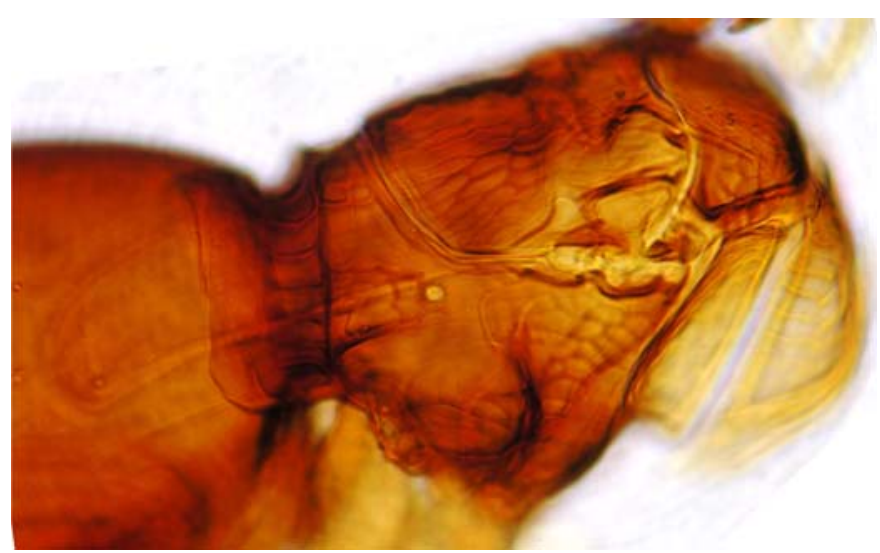

Image 10. Litus triapitsyni Rehmat \& Hayat, sp. nov., female: Thorax and part of $\mathrm{TI}$, dorso-lateral view.

tibia and $1.30 \mathrm{x}$ as long as hind tibia; face with a row denticles. (In sutil: funicle segments all longer than broad, each not less than $2 \mathrm{x}$ as long as broad; clava about $3.5 \mathrm{x}$ as long as broad; fore wing disc apically curved; gaster stated as being a little shorter than mesosoma, mesosoma: metasoma, 157: 145; ovipositor short, occupying about one-third length of gaster, and clearly shorter than mid and hind tibiae, 0.50x of mid tibia and $0.41 \mathrm{x}$ of hind tibia; probably the row of facial denticles absent in sutil).

\section{Litus triapitsyni Rehmat \& Hayat, sp. nov. (Images 7-11, Fig. 2)}

\section{Material examined}

Holotype: Female, 29.x.2008, on slide under 3 coverslips, Koylajol, Guwahati, Assam, India, coll. F.R. Khan. Deposited in NPCI, Reg.No. 13/6/70/4.

\section{Etymology}

This species is named after Dr. S.V. Triapitsyn, Department of Entomology, University of California, Riverside, U.S.

\section{Description}

Female: Length, $0.44 \mathrm{~mm}$, exserted ovipositor, $0.074 \mathrm{~mm}$. (Measured from card-mounted holotype before mounting it on a slide).

This species is very similar to L. huberi Rehmat \& Anis, sp. nov. in body colour, various dimension of body parts, and sculpture, but differs only in the following characters: Anterior margin of frons biconvex with a row of large denticles; funicle segments (Image 7) all longer than broad, F1 about 1.5x, F2

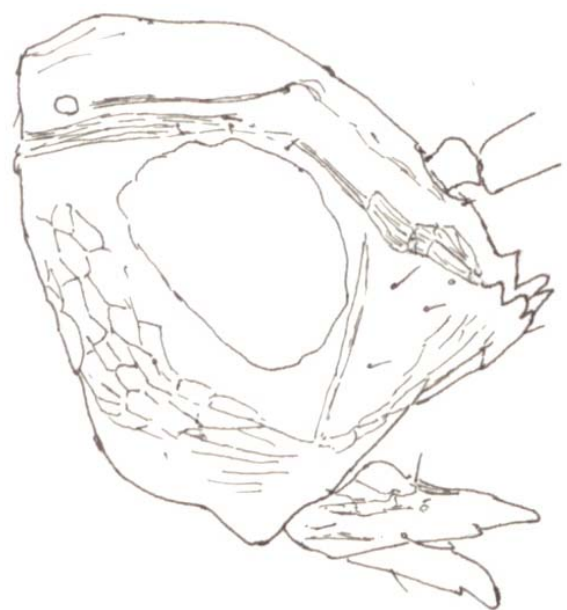

Figure 2. Litus triapitsyni Rehmat \& Hayat, sp. nov., female: Head, dorso-lateral view.

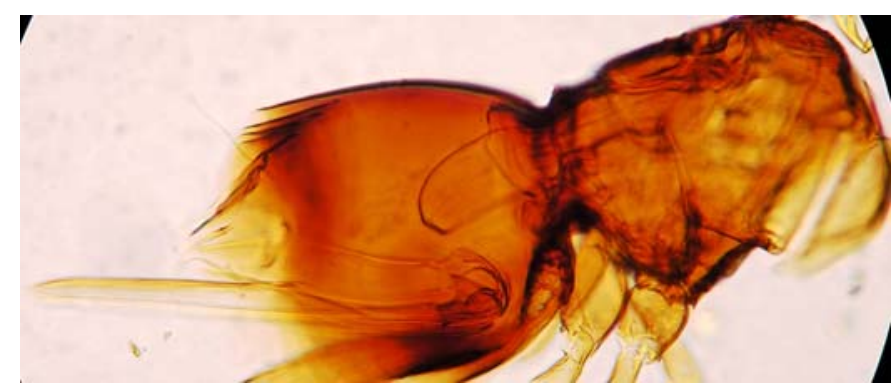

Image 11. Litus triapitsyni Rehmat \& Hayat, sp. nov., female: Thorax and gaster, dorso-lateral view.

and F3 2x, F4 1.75x, and F5 and F6 each a little longer than broad; clava $2.3 \mathrm{x}$ as long as broad; ovipositor originates from near base of gaster, and strongly exserted at apex, the exserted part $0.39 x$ of gaster length (Image 11). Structural details are illustrated in Images 7-11 \& Fig. 2.

Relative measurements (holotype slide): Thorax length, 57; gaster length, 74; ovipositor length, 95; mid tibia length, 48; mid tarsus length, 40; hind tibia length, 64; hind tarsus length, 60. Fore wing length, 184; fore wing width at widest, 10; width at widest part of disc, 7.5; marginal fringe length, 70; hind wing length, 180; hind wing width, 6; marginal fringe length, 70 .

Male: Unknown.

Host: Unknown.

Comments: This species is very close to L. huberi, Rehmat \& Anis, sp. nov., but different in having the anterior margin of frons with two convex lobes provided with large denticles; ovipositor originates from near base of gaster, and strongly exserted at apex, exserted part 0.39x of gaster length; ovipositor $1.98 \mathrm{x}$ as long as mid tibia and $1.48 \mathrm{x}$ as long as hind tibia. [In huberi: anterior margin of frons slightly convex, with a row of large denticles; ovipositor originates from basal fourth of gaster and very slightly exserted, the exserted part about $0.17 \mathrm{x}$ of gaster length; ovipositor $1.65 \mathrm{x}$ as long as mid tibia and $1.30 \mathrm{x}$ as long as hind tibia]. 


\section{References}

Gahan, A.B. \& M.M. Fagan (1923). The type species of the genera of Chalcidoidea or chalcid-flies. United States National Museum, Bulletin No. 124: 1-173.

Haliday, A.H. (1833). An essay on the classification of the parasitic Hymenoptera of Britain, which corresponds with the Ichneumones minuti of Linnaeus. Entomological Magazine 1: 259-276, 333-350.

Howard, L. O. \& W.H. Ashmead (1896). On some reared parasitic hymenopterous insects from Ceylon. Proceedings of the United States National Museum 18: 633-648.

Oglobin, A.A. (1935). Um (sic) nuevo mimórido de Misiones (Hym. Mymaridae). Revista de Entomologia 5: 59 -64.

Triapitsyn, S.V. \& V.V. Berezovskiy (2004). Review of the genus Litus Haliday, 1833 in the Holarctic and Oriental regions, with notes on the Palaearctic species of Arescon Walker, 1846 (Hymenoptera: Mymaridae). Far Eastern Entomologist, Vladivostok No. 141: 1-24. 